\title{
Specific Features of State Regulation of Operations with Cryptocurrencies in the Conditions of Digitalization
}

\author{
Submitted 27/01/19, 1st revision 26/02/19, 2nd revision 30/04/19, accepted 05/06/19
}

\author{
I.N. Efremenko ${ }^{1}$, V.A. Bondarenko ${ }^{1}$, A.Ya. Palant ${ }^{1}$, G.V. Nazarenko ${ }^{2}$
}

\begin{abstract}
:
Purpose: The article investigates specific features of state regulation of operations with cryptocurrencies in the conditions of the world economy digitalization.

Design/Methodology/Approach: In order to form the state regulation of operations with cryptocurrencies, which create additional risks for the national currencies functioning in international financial and credit relations, it is necessary to consider this phenomenon first, from the position of a complete ban on the use of cryptocurrencies as a means of payment, second, in combination of a ban on the use of cryptocurrencies as means of payment, third, from the possibility of expanding the range of cryptocurrency users by including legal entities into it and fourth, the full legalization of the cryptocurrency.

Findings: The authors developed and proposed a set of measures aimed at the formation of common standards and norms of state regulation of operations with cryptocurrencies in international financial relations.

Practical Implications: The results of the study can be applied in the development of legal regulation of virtual currencies not only at the national level, but also at the international level.

Originality/Value: The main contribution of the study is to identify possible risks in the sphere of state regulation of cryptocurrencies based on the experience of some countries: from formal permission (including recommendations on possible risks) or the application of general principles of regulation in the field of payments to the complete ban of such activities.
\end{abstract}

Keywords: Blockchain, digitalization of the world economy, world financial system.

JEL codes: G28, F38, F65, H20, O38.

Paper Type: Research article in a Special Issue dedicated to Russian Economy. Section 1: Digital Economy.

${ }^{l}$ D.Sc. in Economics, Associate Professor, Department of Financial Monitoring and Financial Markets, Rostov State University of Economics, Rostov-on-Don, Russian Federation, efremenko@yandex.ru

${ }^{l}$ D.Sc. in Economics, Associate Professor, Head of the Department of Marketing and Advertising, Rostov State University of Economics, Rostov-on-Don, Russian Federation. ${ }^{1}$ Post-graduate of the Department of Financial Monitoring and Financial Markets, Rostov State University of Economics, Rostov-on-Don, Russian Federation.

${ }^{2}$ Chief Specialist of the Regional Support Department JSB «Sobinbank», Moscow. 


\section{Introduction}

One of the key areas of the improvement of world economy today is the development of digital innovation technologies and their application almost in all its sectors. The accelerating digitalization of modern society, the penetration of information and telecommunication technologies into all spheres of its life created objective prerequisites for a new stage of the technological development - the creation of a digital economy. We can observe its most noticeable manifestation in the financial sector of the world economy although network analysis and big date processing is also required (Polyakova et al., 2019).

This innovation process spread has affected all the countries and regions of the world. Currently, the share of the digital economy in the gross domestic product of all developed economies is growing and according to analysts of Gartner (2019) by 2025, the digital transformation will affect all the areas of most countries. Today, in the conditions of the world economy global digitalization, the global financial system is being transformed from a system that consolidates national currency systems to a multi-currency system based on the extensive use of innovative information and telecommunication technologies, while there is an active discussion of possible difficulties and problems associated with the use of cryptocurrencies for servicing trade and economic operations both at the national level and at the international one.

The concept of "cryptocurrency" appeared due to high achievements in computer technology and computer science, as well as in Cryptography and Economics. The basis for the creation of the cryptocurrency is the blockchain technology. Cryptocurrencies, actively conquering the world, and now are the cause of violent disputes. There is a gradual expansion of the market of the use and the involvement of new segments of the world economic market, even with existing disagreement. The world financial system has received a qualitatively new tool - cryptocurrency, which has the characteristics of a higher degree of perfection, simplifying payment transactions by eliminating intermediaries and at the same time, giving anonymity to operations, which is expected and natural. The analysis of existing cryptocurrencies shows that it is impossible to predict the leading position of any single cryptocurrency in the global financial system at the moment, but in fact, a new type of currency confidently takes its place in the daily life of businesses and citizens.

\section{Theoretical, Informational and Empirical, and Methodological Grounds of the Research}

Modern life is characterized by the rapid development of electronic technologies, the active use of which over the past few years has practically allowed to fully realize the idea of private money on the basis of a fundamentally new technological solution, laid in the basis of bitcoin, which gave this digital currency a number of undoubted advantages over traditional (Fiat) money, provided absolute freedom of money 
transfers. According to Leon Lowe, the nominee for the Nobel peace prize, "Every informed person should know about Bitcoin, because it can be one of the most important events in the world" (Happycoin, 2019). The blockchain open source has caused endless replication of the most diverse in their characteristics altcoins that have flooded the digital economy. In a short period, the actual multi-currency monetary systems became a reality. Along with national payment systems based on the use of legal means of payment, alternative payment systems based on the use of cryptocurrencies are actively developing. Individuals massively carry out the issuance of various kinds of cryptocurrencies, which are virtual representatives of the "electronic cash".

The business community can already start introducing cryptocurrencies into commercial activity, and the largest banks are thoroughly studying the possibilities of blockchain technologies, positioned by fintech-industry as one of the most promising trends of our time (Figure1). And only the lack of legal certainty regarding cryptocurrencies prevents the wider introduction of this technology (Tihonov, 2016).

Figure 1. The amount of money in the world, in US dollars

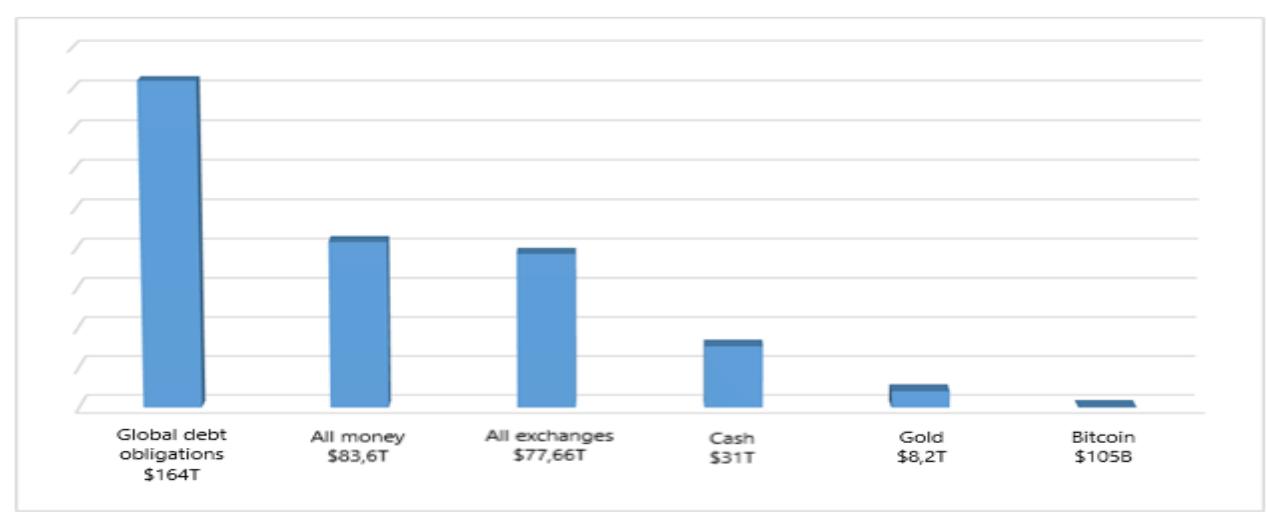

The active development of new digital technologies sets the task for the legislator to create a qualitatively new model of their legal regulation and minimization of criminological risks. But at the moment, states have not only solved this problem, but have not even got close to understanding its importance. This is evidenced by the lack of an unified approach to establishing the legal nature of cryptocurrencies, common standards for countering the legalization of criminal proceeds and the financing of terrorism in their turnover (hereinafter-ML/TF) and the universal strategy for forming a system for introducing virtual currency into the Fiat currency.

Considering all this, there is an urgent need to understand the new payment phenomenon from the standpoint of the state regulation of public relations arising in connection with the use of private money in electronic form. The most important aspect of the legal regime of the cryptocurrency is its qualification as an object of civil rights, which not only has a general legitimizing effect on the relevant transactions, 
but also sets the vector of regulation of cryptocurrencies in the entire system of international law.

Today, there is a paradoxical situation when, along with Fiat payment systems, individuals have created alternative not controlled by public legal entities payment systems that are developing. If in the first case, the money circulation is provided by legal means of payment, in the second one it is provided by alternative means of payment, including various cryptocurrencies. It is obvious that the use of cryptocurrencies as means of payment largely contradicts the paradigm of the exclusivity of the monetary sovereignty of states. This poses a dilemma how national authorities should treat such practices and in what direction the relevant legal regulation should be pursued. In the most general form, one of the possible approaches is to establish a strict ban on the use of cryptocurrencies, the other one comes from the possibility to legalize their turnover in one way or another. Today, most countries of the world have not yet chosen the direction of the relevant state policy. In the legal sector, cryptocurrencies as means of payment are intensively used on the commercial platforms of the so-called digital economy, which is associated with the creation of various virtual values, their capitalization in Fiat currency is rapidly growing (Figure 2).

It seems obvious that the use of cryptocurrencies as a payment for goods, works and services creates direct competition with legitimate means of payment, since in this case, along with them, there arise illegal means of payment which are operated by economic agents. It is known that the purpose of any state is to ensure and to protect economic sovereignty, according to the principle of implementation of which the monetary circulation should be based on the use of exclusively legal means of payment. At the same time, the flow of these funds is provided by the activity of national (central) banks and authorized credit organizations, as operators of national payment systems. Thus, the existence of private off-Bank electronic payment systems operating based on the cryptocurrencies use calls into question the above-mentioned principle of the organization of monetary circulation.

Figure 2. Cryptocurrency capitalization, billion USD (WB, 2019)

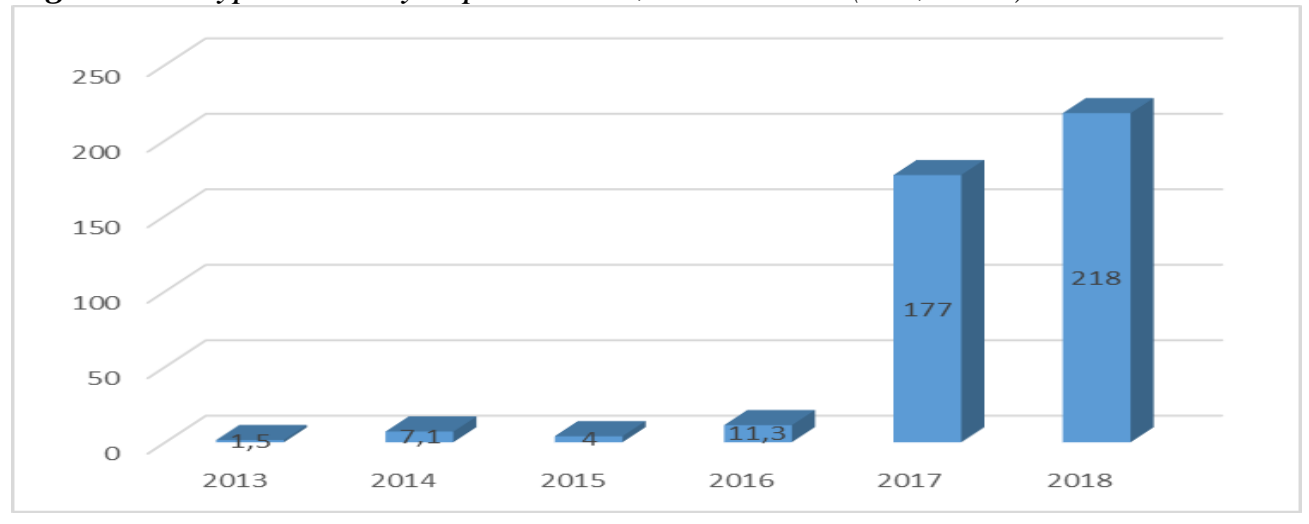


Today, the process of interaction between national currencies and cryptocurrencies has received one more important direction of development. National (central) banks of some states announced the possibility in the foreseeable future of issuing national cryptocurrencies. Since October 2018 the first national cryptocurrency was officially launched in Venezuela. The state guarantees the mandatory acceptance of new means of payment, along with the national currency - the Venezuelan Bolivar, throughout the country (Riafan, 2018). Thai authorities also announced their intention to introduce their national cryptocurrency to support the economy (VC, 2018).

In January 2019, Saudi Arabia and the United Arab Emirates (UAE) has announced about their plans to create a cryptocurrency. At the experimental stage, cross-border digital currency will be strictly focused on banks in order to better understand the consequences of blockchain technology and facilitate cross-border payments (RBC, 2019). In Australia, some political parties require the acceptance of bitcoin as a national currency, and also call on the Central Bank of this country to consider the possibility of issuing a national cryptocurrency, and since July 1, 2017, bitcoin has received the status of ordinary money (BTC, 2019). The people's Bank of China in order to develop the system of electronic payments together with several commercial banks of the country began to carry out "transactions on paper" in order to test the prototype of the national cryptocurrency (Forklog, 2017).

The Bank of Russia has also started to analyze the possibility of creating the domestic cryptocurrency based on the technology of distributed registries. However, it should be noted that the attitude towards national cryptocurrencies is ambiguous. Thus, the report of the Bank for international settlements notes that cryptocurrencies issued by Central banks can disrupt the stability of the global financial system, as they can create competition for Fiat money. In turn, this may lead to increase interest rates, as traditional money will be "removed" from the system of commercial banks, which can destabilize them.

It is predicted that the introduction of national cryptocurrencies may cause fundamental problems beyond the payment systems and mechanisms of monetary policy. Also, according to researchers, cryptocurrencies of Central banks can lead to instability in the activity of commercial banks. In addition, the introduction of such instruments will lead to a significant increase of the Central banks role in the financial system (BIS, 2018). The official issuance of such currencies, in our opinion, may lead to a certain leveling of the differences between public and private electronic means of payment, but it does not exclude them at all.

In the meantime, cryptocurrencies are used as alternative (private) payment systems operating because of the already mentioned innovative blockchain technology. Today, it is hardly possible to predict with enough accuracy how the confrontation between the state and alternative payment systems will finish at last. It is also hard to predict financial crises (Thalassinos and Thalassinos, 2018). However, in any case, public 
relations arising in connection with the use of cryptocurrency as a means of payment or investment instruments cannot be formed outside the legal field, therefore, they require legislative regulation.

\section{Results}

Most countries of the world do not prohibit the use of cryptocurrencies but try form the legal basis for it. There are considered the following variants of a cryptocurrency substantiation: commodity (such as an exchange instrument, for example, in the USA), a financial instrument, foreign currency transactions (as it was defined by the Russian Federal Antimonopoly Service), means of payment. Moreover, as noted by the head of the group on providing legal services for technological projects Deloitte Artem Tolkachev, "the characteristics of cryptocurrencies as a means of payment in combination with the functions of cryptocurrencies for storage and accumulation of value actually put equality between cryptocurrencies and money, and as the next step the accepting of cryptocurrencies as a cash surrogate, that no one would like" (Pertsova, 2017). Meanwhile, practice shows that the cryptocurrency is used both as a commodity with which "speculative" income is invested and got, and as a means of payment for goods and services in the Internet space.

Currently, the process of legislative registration in many countries has not yet started, and only some jurisdictions have begun legal regulation of the crypto environment. Many countries are looking for approaches for regulating the cryptocurrencies circulation. They are just beginning to create the necessary legislative conditions and regulatory framework; the only question is what approaches will be taken as a basis. It is also important to note that in those countries where there is no regulation of the crypto industry, there are various recommendations from Central banks and other official government bodies on consumer protection. There are four main approaches that are used by national regulators in the sphere we are analyzing. The most conservative approach seems to be that establishes a complete ban on the use of cryptocurrency as a means of payment or introduces a restriction on transactions with them.

Such an approach is currently practiced by some countries of the world, including Algeria, Bangladesh, Bolivia, Brazil, Vietnam, Egypt, India, Indonesia, Jordan, Iceland, Italy, Kyrgyzstan, Luxembourg, Morocco, Mexico, Nepal. Thus, states are trying to neutralize the threat to the stability of the national currency, which is carried by alternative means of payment, to eliminate the risks of financial losses for users, to prevent the use of cryptocurrency for illegal export of capital, money laundering and financing of terrorism. In establishing such prohibitions, the risks associated with the use of cryptocurrencies are absolutized, and their useful functions that could be used in the interests of the development of settlement relations are ignored. We believe that the establishment of such a strict ban seems unnecessary and impractical, since its implementation is extremely difficult, because it is almost impossible to stop 
operations with cryptocurrencies. In addition, in this case, the cryptocurrency turnover will be completely shadow, and it should be carried out with jurisdictions that provide a more favorable legal regime. A milder version of the above approach is a legal structure that combines a ban on the use of cryptocurrencies as means of payment with the granting of the right to individuals to purchase and dispose cryptocurrencies, including for the national currency.

Such an approach is particularly perceived in China, where there is a ban on transactions with cryptocurrencies for business entities, but there are no restrictions on the use of alternative means of payment for citizens. This approach on default has been established also in a number of other countries due to the fact that their legislation at first did not provide for appropriate prohibitions, and individuals according to a general rule are free to make deals with all the property, which is in accordance with the legislation is not limited in the civil law.

The following approach, in contrast with the previous one, is based on the possibility of extending the circle of the cryptocurrency users due to the inclusion of legal entities which are granted the right to acquire and dispose of it legally for the national currency. To date, such a variant of legal regulation has been established in the Republic of Belarus and it provides for the use of a high-tech Park operating based on the principle of extraterritoriality. Thus, according to paragraph 2 of the Decree of the President of the Republic of Belarus from 21.12.2017 №8 "On the development of the digital economy" individuals have the right to own digital signs (tokens) and to make such operations as mining, storage in virtual wallets, exchange of some digital signs for others, purchase and alienate them for Belarusian rubles, foreign currency, electronic money, as well as to give and bequeath.

In turn, legal entities have the right to own digital signs and through a resident of the hi-tech Park to create and place their own tokens in the Republic of Belarus and abroad, to store tokens in virtual wallets. In addition, they are granted the right through cryptopleura operators, the exchange operators of cryptocurrency, other residents of the Park of high technologies, carrying out the activity, to acquire, to dispose tokens, to make any other transaction (operation) with them. The fulfilment is associated with the moment of reflection of the confirmed operation on the transfer of a digital sign to the addressee in the register of transaction blocks (blockchain), another distributed information system according to the rules (protocols) in force in them. As we can see, in this case, cryptocurrency transactions are associated with a certain location, and their fulfilment involves mandatory mediation of residents of the hi-tech Park in transactions and operations. A significant disadvantage of this approach is that the cryptocurrency payment function is still not implemented. New virtual entities are involved into the turnover only as a commodity or financial asset, although cryptocurrencies have a rather high potential for the use in the digital economy as a means of payment. 
Finally, the fourth option of the possible ones is based on the full legalization of the cryptocurrency with the right to individuals and organizations not only to legally acquire and alienate electronic signs of value for the national currency, but also to use as a means of payment in accordance with the legislation.

This approach allows to fully implement the payment function of the cryptocurrency giving it the status of a special means of payment. Legally the cryptocurrency payment function at first was held in Japan. On May 25, 2016 the National Assembly of this country adopted a legislative act regulating the activity of operators of cryptocurrency exchanges, according to which they are obliged to register their activity in the Financial Services Agency, which in turn is authorized to administer the relevant trading platforms. Banks are given the opportunity to make payments using cryptocurrencies, which are defined as means of payment (Forklog, 2016).

Virtual currency in this country is defined as the currency that exists in the form of a record on an electronic device, except any Fiat currency (Japanese or other one) that can be used to pay for purchased or rented goods/services. As we can see, this approach based on the official acceptance that, along with the national currency and currencies of foreign countries, in the calculations in accordance with the contract, cryptocurrencies also can be used as means of payment.

As for the Russian Federation, it should be noted that operations with cryptocurrencies are not regulated at the legislative level. Now, the status of cryptocurrencies is being discussed, and the Central Bank of Russia does not intend to prohibit the use of bitcoin. Even though there was rhetoric at the state level about the high risks of the cryptocurrencies use, a decision on the state regulation of mining, circulation, purchase and sale of cryptocurrencies was made. Now, there is an active discussion of the draft law "On digital financial assets", which defines the concept of "digital financial asset", while it emphasizes that digital financial assets are not a legal means of payment in Russia (Valdai DC, 2018). Among the priorities of state regulation of the cryptocurrency sphere it is also necessary to highlight the consequences of transactions with virtual currency for tax purposes.

There is a quite popular view that cyberspace is so self-sufficient and extraterritorial that it excludes the very question of the need to pay taxes. Indeed, tax administration of income from the digital economy today faces significant challenges in establishing taxable persons and determining the amount of taxes due from them. This is contrasted with the idea of new fiscal levies, which, as a source of budget revenues, could simultaneously serve as a means of limiting the use of alternative means of payment. In relation to the world-famous cryptocurrency of bitcoin, along with regulatory prohibitions on transactions with it, it is proposed to introduce an appropriate tax (Kuznetsov and Yakubov, 2016). 
Approaches to tax regulation of operations with cryptocurrencies in the countries of the world differ from each other and, according to Kucherov and Khavanova (2017), and most of these approaches have not received the legislative consolidation. It can be argued that these approaches are still indicated mainly in departmental documents. For example, the tax services of several countries, including Australia, the United Kingdom, Norway, Singapore, the United States - have developed departmental regulations, prepared official explanations, formulating their approaches to the taxation of transactions using bitcoin.

The main feature of alternative means of payment, as we have already mentioned, is that their use is not covered by currency-legal and monetary regulation. After all, today in many countries of the world cryptocurrency is not recognized as an official means of payment, and electronic money. This is very important, since at the taxation the appropriate cryptocurrency transactions can't be classified as remittances. In this connection, a legal position was outlined, according to which cryptocurrencies are not money from a legal point of view.

And since cryptocurrency is not a legal means of payment, the tax authorities are forced to develop an appropriate conceptual apparatus in order to identify income from cryptocurrency transactions for tax purposes. At the end, there has emerged a common approach, according to which bitcoin is positioned as an "economic asset". Thus, according to the official position of the US internal revenue service, bitcoin is not a currency for tax purposes, but it is accepted as an object of ownership (GLR, 2014). In a situation where the cryptocurrency is not a means of payment, there are good reasons for positioning transactions with it as transactions of a barter nature.

This conclusion follows from the principle of prevailing a substance over a form, which is characteristic of tax and legal assessment. This approach especially at first was accepted by the tax authorities of several countries. Thus, the Australian Tax service initially did not consider bitcoin as a means of payment, equating operations with its use to barter transactions. As for the activity of issuing bitcoins, the income from the transfer of virtual currency to a third party was considered as taxable, while the costs connected with the activity of its "extraction" were allowed to be deducted when calculating the tax base (Australia CC, 2018).

The tax service of Israel in 2017 published a draft of circular, according to which the cryptocurrency is considered as digital unit with a nominal value that can be used for barter or for investment. At the same time, for tax purposes alternative means of payment are defined as an asset (BNA, 2018).

In turn, the Tax service of Canada recognizes taxpayers as subjects of transactions made with the use of cryptocurrencies, while the taxation rules are differentiated depending on whether the cryptocurrency is used as "money" in payments for purchased goods (works, services), or itself is purchased for speculative purposes. In 
the first case, there are applied the rules on transactions of a barter nature, in the second one the approaches developed for transactions with securities (Canada CC, 2017). According to foreign experts, the tax policy and legislation of the countries are mostly developed without considering the peculiarities of operations with virtual currencies. However, the fact that bitcoin is not recognized as money (in legal and economic terms) does not exclude the taxation of income received as a result of transactions with it. Selling goods for bitcoins thus is a barter transaction.

The issue of taxation of transactions with using cryptocurrencies with value added tax (VAT) deserves special attention. Legal approach is generally accepted in accordance to which there is no value added tax on transactions related to the provision of payment services. Thus, the legislative recognition or, on the contrary, the nonrecognition of the payment function of the cryptocurrency in the first case may lead to the refusal to charge VAT, and in the second one to carry out such a charge. Primarily budget income depends on this, but this factor is not decisive. Charging VAT from operations on the transfer of cryptocurrency excludes its use as a means of payment. In other words, the implementation of the payment function of alternative means of payment is dependent on whether the relevant transfers are subject to this tax or not. This aspect of taxation should be recognized as key.

The fact is that the identification of the cryptocurrency as a product or service for VAT purposes does not fully correspond to the peculiarities of the legal structure of this tax and, in fact, does not consider the payment function of the cryptocurrency. For example, the precedent is the decision of the European Court of Justice from October 22, 2015 in the case of Skatteverket (Court, 2015), in which bitcoin is characterized as a "contractual" means of payment, acting in such a way in the relations between persons who agreed to consider it in this way.

In turn, this decision was preceded by a dispute between the Swedish tax authority and the Swedish bitcoin operator, in which the latter disputed the VAT claims. Analyzing the provisions of Directive 2006/112/EC (EU VAT Directive), according to which transactions involving the transfer of currency, banknotes, coins used as a legal means of payment are not subject to taxation, the European Court of Justice found that Bitcoin as such is used mainly for payment transactions between individuals via the Internet and only in specific online stores that accept such currency. The court made the conclusion that virtual currencies can be defined as a type (type) of electronic money not regulated in legislation, which are emitted and controlled by their developers and accepted by users of such a specific virtual system (Bondarenko et al., 2017). Such virtual currencies are similar (equivalent) to official convertible currencies, which is confirmed by the practice of their respective use.

However, virtual currency differs from electronic money if virtual currency is not presented in the traditional settlement units. In view of this, it is decided that any currency or means of payment, even if it is not a legal means of payment, is subject 
to this tax form, provided that it is used as a means of payment and it is accepted as such by the parties of the transaction. It is obvious that the nature of the analyzed relations is only in money transfer. Thus, after investigating the legal nature of bitcoin, the European Court at last accepted the cryptocurrency as a means of payment for VAT purposes, not a commodity/service. The position of the European Court of Justice described above has had a direct impact on the practice of taxation of cryptocurrency transactions in some countries.

Thus, in September 2016, the Italian tax service issued a guide for business on VAT taxation of transactions with bitcoins, according to which transactions with bitcoins should be qualified as services which are not subject to this tax (VAT, 2016). A similar approach prevailed in Germany. Thus, in the circular of the Ministry of Finance of this country dated 27 February 2018, the legal position of the European Court of Justice dated 22.10.2015 was adopted, according to which for tax purposes transactions with the use of cryptocurrencies are defined as payment services, consequently, should not be subject to value added tax. According to this, cryptocurrency is classified as the equivalent of legal means of payment and cryptocurrency transactions are positioned as a contract-based alternative payment method. We believe that the acceptance of the payment function of the cryptocurrency for tax purposes serves as a good ideological basis for legitimizing it as a means of payment.

\section{Conclusions and Recommendations}

Thus, the regulation of operations with cryptocurrencies within the global financial system should be carried out at the interstate level in a number of directions, while the goal of each direction should be the elimination of the existing legal gaps that create obstacles to the stable and sustainable development of payment systems for operations with cryptocurrencies. This requires:

$\checkmark$ to define crypto-currencies and consolidate on the international level as an object of civil rights;

$\checkmark$ to separate cryptocurrencies into an autonomous group of financial instruments, thus detaching them from cash surrogates;

$\checkmark$ to assign the status of the payment instrument, as well as to include into the list of currency values;

$\checkmark$ to give the status of a separate segment of the world financial system to private payment systems, fixing this position in the documents of international financial institutions;

$\checkmark$ to accept operations with cryptocurrencies as a rightful form of non-cash payments;

$\checkmark$ to form international financial institutions or empower existing ones to act as providers for virtual currency wallets;

$\checkmark$ to define cryptocurrency transfer operations as commercial payment services; 
$\checkmark$ to determine the procedure for the use of virtual currencies as monetary meters in international financial reporting standards;

$\checkmark$ to develop a set of measures to improve the financial security of operations with cryptocurrencies, including international currency and tax legislation in order to counteract the laundering of proceeds from crime and the financing of terrorism.

This set of measures will allow to develop common universally accepted standards and norms of state regulation of transactions with cryptocurrencies, which will serve as the basis for the development of legal norms individually by each state, taking into account the individual country features of the normative-legal regulation of the financial sector of the economy. The recognition of cryptocurrency as a means of payment and an object of property rights, the involvement of the state into the process of its regulation in terms of increasing the security of transactions, as well as ML/TF will serve as the basis for the formation of a global payment system functioning anywhere for 24 hours a day.

According to the results of our study, we note that nowadays there are no uniform standards in the state regulation of cryptocurrencies and the financial regulator of each individual country is guided by its own approaches: from formal permission (including recommendations for the industry about possible risks, research in this area, etc.) or the application of common principles of regulation in the field of payments to a complete ban of such activity. If we consider what consequences may be in terms of formal permission to operate with digital currencies, Central banks, adhering to this approach, should pay attention to the negative statistics of digital exchanges bankruptcies (including those associated with fraud and hacker attacks).

The solution to these problems could be the licensing of the activity related to virtual currencies, for example, the activity of virtual currency exchanges; admin and emission of virtual currencies, storage and management by third parties. The complete ban on these activity in the conditions of the global regulatory trend for the formal permission of such activity under special licenses can lead to the curtailment of innovative projects in this area and transfer them to a more transparent regulatory jurisdiction. There is also an open question, interlinked with the regulatory theme the need for taxation of transactions with virtual currencies and, accordingly, the acceptance of transactions with bitcoins as a banking operation carried out with the use of an electronic means of payment.

\section{References:}

Australia CC. 2018. Tax Treatment of Crypto-currencies in Australia - Specifically Bitcoin. Available at: www.ato.gov.au/misc/download/pdf/qc42159.pdf.

BIS. 2018. Central Bank Digital Currencies. Bank of International Settlements, March 2018, available at: www.bis.org/cpmi/publ/d174pdf.

BNA. 2018. Israel Seeks Tax on Bitcoin, Virtual Currency Transactions. Available at: 
www.bna.com/israel-seeks-tax-n7301445014/.

Bondarenko, V.A., Israilova, E.A., Albekova, S.A., Albekova, A.A. 2017. Difficulties and Perspectives of Incorporating Russian Economy and Centripetal Tendencies in the EU. European Research Studies Journal, 1(20), 56-63.

BTC. 2019. Where Bitcoin is a National Cryptocurrency? Available at: www.howtobuycoin.com/bitcoin/bitcoinofficial-cryptocurrency/.

Canada CC. 2017. Legal Regulation of Operations with Cryptocurrencies in Canada. Available at: www.eternitylaw.com/konsalting-kriptovalyut/blog-pravovoeregulirovanie-kriptovalyutnyh-operatsij-v-kanade.

Forklog. 2016. Japan Adopted the Law on the Regulation of Cryptocurrency Exchanges. Available at: www.forklog.com/yaponiya-prinyala-zakonregulirovaniikriptovalyutnyh-birzh.

Forklog. 2017. The Central Bank of China Announced the Need for the Speedy Launch of a National Cryptocurrency. Available at: www.forklog.com/tsentrobank-kitaya-zayavilo-neobhodimosti-skorejshegonatsionalnoj-kriptovalyuty/.

GLR. 2014. Regulation of Bitcoin in Selected Jurisdictions. Report for Congress, The Low Library of Congress, Global Legal Research Center, LL File 2014-010233.

Happycoin. 2019. Twelve Statements about Bitcoin and Blockchain. Available at: www.happycoin.club/12-vyiskazyivaniybitkoine-i-blokcheyne-rekomenduemyie-kprochteniyu.

Kucherov, I.I., Khavanova, I.A. 2017. Tax Implications of Using Alternative Means of Payment (Theoretical and Legal Aspects). Bulletin of Perm University, Law, 35, 3543.

Kuznetsov, V.A., Yakubov, A.V. 2016. About Approaches in the International Regulation of Cryptocurrency (Bitcoin) in Certain Foreign Jurisdictions. Money and Credit, 3, 20.

Pertsova, V. 2017. Regulation of Cryptocurrency: Will the State Be Led by a Process That Cannot Be Stopped. Forbes, 8 February, available at: www.forbes.ru/biznes/338503regulirovanie-kriptovalyutvozglavit-li-gosudarstvokotoryy-nelzya-ostanovit.

Polyakova, A.G., Loginov, M.P., Serebrennikova, A.I. \& Thalassinos, E.I. 2019. Design of a socio-economic processes monitoring system based on network analysis and big data. International Journal of Economics \& Business Administration, 7(1), 130-139.

RBC. 2019. Saudi Arabia and the UAE Announced the Creation of a Joint Cryptocurrency. Available at: www.rbc.ru/rbcfreenew/5c4402769a7947432e032d29.

Riafan. 2018. The first National Cryptocurrency Launched in Venezuela. Available at: www.riafan.ru/1105459-pervaya-nacionalnaya-kriptovalyuta-zapushenavenesuele.

Thalassinos, I.E., Thalassinos, Y. 2018. Financial Crises and e-Commerce: How Are They Related. Available at SSRN: https://ssrn.com/abstract=3330169.

Tihonov, I. 2016. Preface to the Book by N. Popper "Digital Gold: The Incredible History of Bitcoin. Moscow, 8.

Valdai DC. 2018. Report of the International Valdai Discussion Club. Blockchain and Cryptocurrency: a Review of Trends and Prospects, August, available at: www.ru.valdaiclub.com/file/21191/.

VAT. 2016. Italian Tax Authorities Clarify VAT Treatment of Bitcoin Transactions. EY Global Tax Alert Library, Indirect Tax Alert, 27 September.

VC. 2018. National Cryptocurrency of Thailand. Available at: www.vc.ru/crypto/44463nacionalnaya-kriptovalyuta-tailanda-krupneyshaya-mayning-ferma-v-rossii-i-drugienovosti-blokcheynakriptovalyut.

WB. 2019. The World Bank's official website. Available at: http://www.worldbank.org. 